\title{
EVALUATING THE IMPACT OF LASRC AND SEN2COR ATMOSPHERIC CORRECTION ALGORITHMS ON LANDSAT-8/OLI AND SENTINEL-2/MSI DATA OVER AERONET STATIONS IN BRAZILIAN TERRITORY
}

\author{
Rennan F. B. Marujo ${ }^{\mathrm{a}, \mathrm{b} *}$, José G. Fronza ${ }^{\mathrm{a}, \mathrm{b}}$, Anderson R. Soares ${ }^{\mathrm{a}}$, Gilberto R. Queiroz ${ }^{\mathrm{a}}$ and Karine R. Ferreira ${ }^{\text {a }}$ \\ ${ }^{a}$ National Institute for Space Research (INPE); \\ \{rennan.marujo, jose.fronza, anderson.soares, gilberto.queiroz, karine.ferreira\}@inpe.br \\ ${ }^{\mathrm{b}}$ Foundation for Science, Technology and Space Applications (FUNCATE); \{rennan.marujo, jose.fronza\}@ funcate.org.br
}

KEY WORDS: Atmospheric Correction, Sentinel-2, LaSRC, Sen2cor, AERONET, Surface Reflectance.

\begin{abstract}
:
Accurate and consistent Surface Reflectance estimation from optical remote sensor observations is directly dependant on the used atmospheric correction processor and the differences caused by it may have implications on further processes, e.g. classification. Brazil is a continental scale country with different biomes. Recently, new initiatives, as the Brazil Data Cube Project, are emerging and using free and open data policy data, more specifically medium spatial resolution sensor images, to create image data cubes and classify the Brazilian territory crops. For this reason, the purpose of this study is to verify, on Landsat- 8 and Sentinel-2 images for the Brazilian territory, the suitability of the atmospheric correction processors maintained by their image providers, LaSRC from USGS and Sen2cor from ESA, respectively. To achieve this, we tested the surface reflectance products from Landsat- 8 processed through LaSRC and Sentinel-2 processed through LaSRC and Sen2cor comparing to a reference dataset computed by ARCSI and AERONET. The obtained results point that Landsat-8/OLI images atmospherically corrected using the LaSRC corrector are consistent to the surface reflectance reference and other atmospheric correction processors studies, while for Sentinel-2/MSI images, Sen2cor performed best. Although corrections over Sentinel-2/MSI data weren't as consistent as in Landsat-8/OLI corrections, in comparison to the surface reflectance references, most of the spectral bands achieved acceptable APU results.
\end{abstract}

\section{INTRODUCTION}

Nowadays, free and open remote sensing data from different satellites and sensors systems are available to users around the world (Kuenzer et al., 2015). These Earth Observation (EO) data provide rich information about Earth surface and atmospheric dynamics. However, the required knowledge to prepare the data, the volume to process it and the tools required for its analysis difficulties researchers from focusing on the results and discussions instead of data preparation. To overcome this limitation, Analysis-Ready Data (ARD) and Earth Observation Data Cubes (EODC) emerged to handle the complex organisation, storage, and processing that it requires.

The Committee on Earth Observations Satellites (CEOS) definition of ARD stands for "satellite data processed to a minimum set of requirements and organized into a form that allows immediate analysis with a minimum of additional user effort and interoperability both through time and with other data sets" (Siqueira et al., 2019). ARD are procedurally generated data that ensures consistency and interoperability from data acquisition to a level required by users, which can be TOA (Topof-atmosphere) reflectance, surface reflectance (SR) or other standardized data (Giuliani et al., 2017). In this context, EODC are a set of images with spatially aligned pixels and one temporal dimension containing a set of values from which time series can be extracted (Appel and Pebesma, 2019, Ferreira et al., 2020). Many initiatives started to create EODC from ARD, the Australian Data Cube (Lewis et al., 2017), Swiss Data Cube (Giuliani et al., 2017), Armenian Data Cube (Asmaryan et al., 2019), Catalan Data Cube (Maso et al., 2019), Africa Regional Data Cube (Killough, 2019) and more recently

\footnotetext{
* Corresponding author
}

the Brazil Data Cube (BDC) (Ferreira et al., 2020). Considering that the correction of the atmospheric effects on optical observations impacts any further quantitative analysis (Vermote and Kotchenova, 2008, Doxani et al., 2018), it is important to validate how it performs to ensure that the input data is adequate.

BDC is a project that is being developed by Brazil's National Institute for Space Research (INPE), since January 2019, that aims to create multidimensional data cubes of analysisready from medium-resolution Earth observation images for all Brazilian territory and to generate land use and cover information from these data cubes using machine learning and satellite image time series analysis (Ferreira et al., 2020). The BDC uses Landsat- 8 and Sentinel-2 images, among other sensors to generate image data cubes. Landsat- 8 is provided by the United States Geological Survey (USGS), which also maintains the Land Surface Reflectance Code (LaSRC) to correct the atmospheric effects of the Landsat- 8 images and more recently also corrects Sentinel-2 images (Vermote et al., 2018) while Sentinel-2 images are provided by the European Space Agency (ESA), which maintains the Sen2Cor to correct the effects of the atmosphere from Sentinel-2 Level-1C (L1C) (Main-Knorn et al., 2017).

This paper presents the results of an extensive validation of the Landsat- 8 and Sentinel-2 atmospherically corrected data, produce by the BDC and used to create data cubes in the Brazilian territory by comparing Landsat- 8 and Sentinel- 2 surface reflectance products and estimated references. For this analysis, two processors were deployed: LaSRC and the Sen2Cor. These processors are in constant development, considering new inputs of atmospheric and terrain parameters and should be constantly inspected and compared with a ground truth reference, to maintain data consistency. 


\section{METHODOLOGY}

The AErosol RObotic NETwork (AERONET), a global network of sun/sky radiometers, provides a long-term, continuous, and accessible public domain data archive for aerosol optical and radiative properties characterization, as AOT and Ångstrom exponents at different wavelengths (Holben et al., 1998). Due to that, five AERONET sites, located in Brazil, were selected to provide reference aerosol optical thickness (AOT) data. The stations are Alta Floresta, Cuiabá Miranda, Manaus EMBRAPA, Itajubá and Rio Branco and can be seen in Figure 1 over the Brazilian territory.

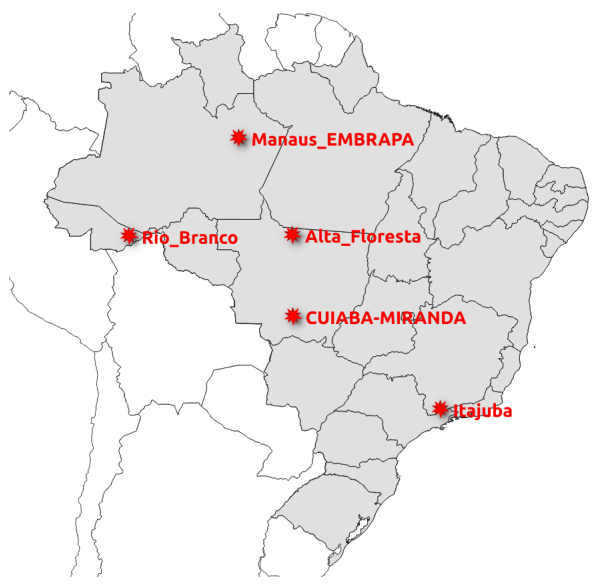

Figure 1. Five AERONET stations: Alta Floresta, Cuiabá-Miranda, Manaus-EMBRAPA, Itajubá and Rio Branco, over Brazilian territory.

The availability of AERONET measurements was used to select images of the same sites and coincident dates from Landsat8/OLI and Sentinel-2/MSI satellite/sensors. Landsat-8/OLI and Sentinel-2/MSI images were selected only if there was an AERONET valid AOT $500 \mathrm{~nm}$ observation on the same day between 10:00 AM to 11:00 AM on a $16 \mathrm{~km} x 16 \mathrm{~km}$ image cropped area centered on the AERONET station. Considering this coincidences and the period ranging from January, 2016 to December 2020, Table 1 shows the number of available scenes for each sensor analysis.

Table 1. Aeronet stations data available considering filter Landsat- 8 and Sentinel-2 daily pass.

\begin{tabular}{|c|c|c|}
\hline Aeronet station & $\begin{array}{c}\text { Landsat-8/OLI } \\
\text { scenes }\end{array}$ & $\begin{array}{c}\text { Sentinel-2/MSI } \\
\text { scenes }\end{array}$ \\
\hline Alta Floresta & 44 & 118 \\
\hline Cuiabá-Miranda & 40 & 80 \\
\hline Itajubá & 52 & 38 \\
\hline Manaus & 10 & 8 \\
\hline Rio Branco & 8 & 3 \\
\hline Total & $\mathbf{1 5 4}$ & $\mathbf{2 4 7}$ \\
\hline
\end{tabular}

It's important to highlight that using AERONET AOT data, with a 1 hour temporal variability (between 10:00 AM to 11:00 AM) from daily satellite passage, it may cause significant uncertainties. Therefore, these temporal discrepancies should be investigated to quantify differences in AOT retrieval by AC processors and AERONET AOT.

Considering that for Landsat-8/OLI and and Sentinel-2/MSI AOT are reported at $550 \mathrm{~nm}$, AERONET $550 \mathrm{~nm}$ AOT was estimated by using the AERONET $500 \mathrm{~nm}$ AOT measurements with the standard Ångstrom exponent interpolation approach, following Equation 1 described by (Doxani et al., 2018, Li et al., 2019, King et al., 1999):

$$
\tau(550)=\tau(500) \tau(500 / 550)^{a},
$$

$$
\text { where } \quad \begin{aligned}
& \tau(550)=\text { interpoled AERONET } 550 \mathrm{~nm} \text { AOT } \\
& \tau(500)=\text { AERONET } 500 \mathrm{~nm} \text { AOT } \\
& a=\text { AERONET } 440-675 \mathrm{~nm} \text { Ångström exponent }
\end{aligned}
$$

The Atmospheric and Radiometric Correction of Satellite Imagery (ARCSI) software uses an implementation of the Second Simulation of a Satellite Signal in the Solar Spectrum (6S) atmospheric correction model, to correct the atmospheric effects (Clewley et al., 2014). The AERONET estimated $550 \mathrm{~nm}$ data was used as input to ARCSI software to generate surface reflectance reference.

Three sets of target surface reflectance images were generated: the first one was Landsat-8/OLI images processed using LaSRC (version 2.0.1); the second was Sentinel-2/MSI images also processed using LaSRC (version 2.0.1); and the third was Sentinel-2/MSI images processed using Sen2cor (mainly version 2.8.0. Although, versions 2.5.5 was used on older images that weren't supported by Sen2cor 2.8.0).

To validate the surface reflectance obtained using LaSRC and Sen2cor processors, the resulted images of each sensor were compared with the ARCSI surface reflectance reference. The comparison analysis was implemented per site, and atmosphere correction method. It is important to note that ARCSI and LaSRC implements the same radiative transfer model, which can be an advantage in its simulation when comparing to atmosphere correction algorithms that uses a different radiative transfer model, i.e., Sen2cor (Doxani et al., 2018). Also, considering that due to differences in atmospheric constituents and lack of comparable data, i.e., water vapour values can only be estimated from Sentinel-2, analysis are hard to perform. Based on that, this study was focused in aerosol, which highly variate in space and time ( $\mathrm{Li}$ et al., 2019), and derived SR products.

Figure 2 presents the workflow used to generate the surface reflectance images and assess the comparisons.

Similarly as in Atmospheric Correction Inter-Comparison Exercise (Doxani et al., 2018) and other previous SR derivations exercises (Ju et al., 2012, Claverie et al., 2015, Vermote et al., 2016, Ilori et al., 2019), the SR products generated LaSRC on Landsat-8/OLI images, LaSRC on Sentinel-2/MSI images and Sen2cor on Sentinel-2/MSI images were compared to a reference dataset, in this case, SR computed by ARCSI using AERONET interpolated AOT data.

For both Landsat-8/OLI and Sentinel-2/MSI, a cloud mask was produced through FMASK 4.2 algorithm (Qiu et al., 2019). This cloud/cloud shadow algorithm was chosen due to its best overall accuracy (Sanchez et al., 2020). This mask was used to remove from both reference and target images the pixels masked as cloud/cloud shadow. Once the mask was applied, the comparison was performed using all Landsat-8/OLI spectral bands, while for Sentinel-2/MSI, due to limitations on ARCSI, the Coastal band was not considered. Per pixel comparison was performed computing the statistical metrics accuracy (A), precision $(\mathrm{P})$, and uncertainty $(\mathrm{U})$ as specified in the following equations: 


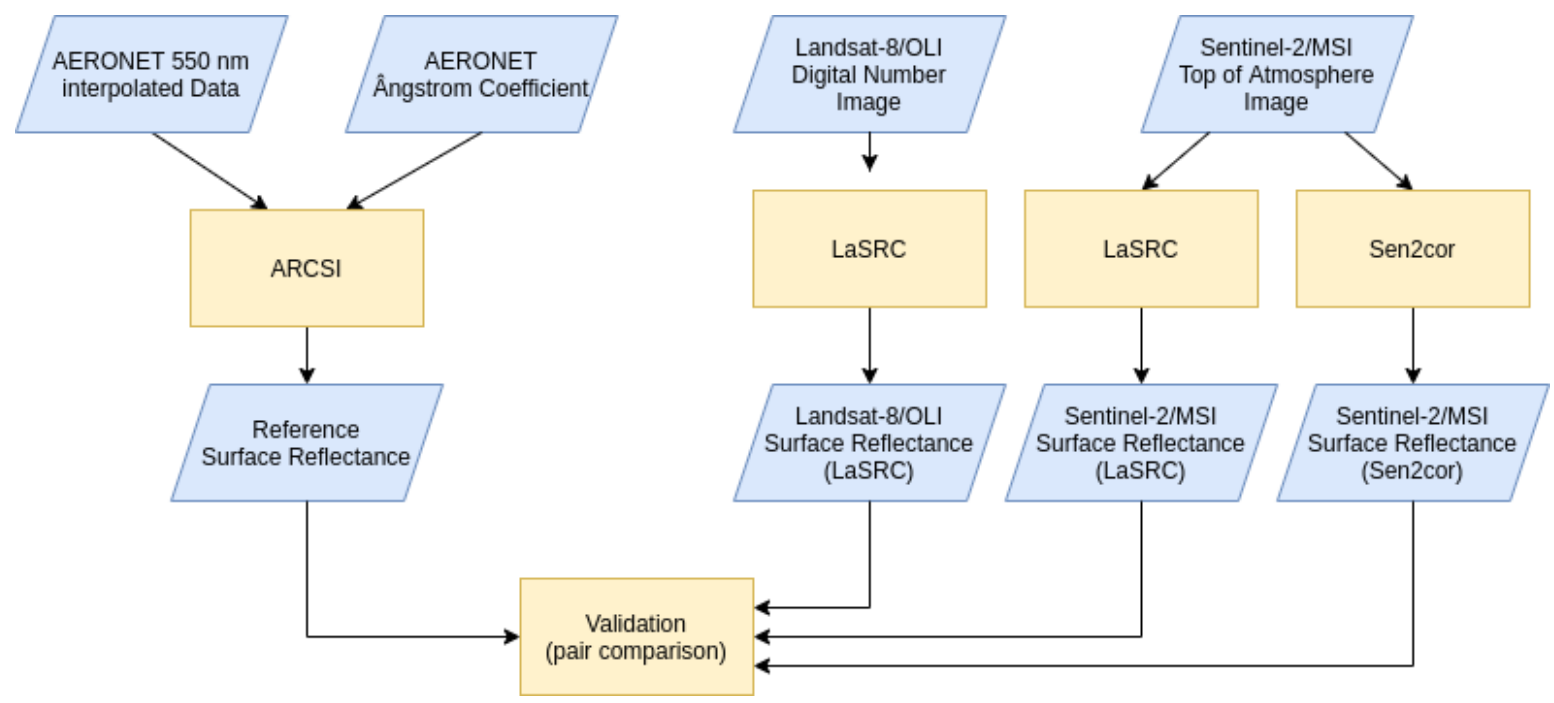

Figure 2. Methodology diagram containing surface reflectance images generation and validation.

$$
\begin{gathered}
A=\frac{\sum_{i=1}^{N}\left(\mu_{i}^{e}-\mu_{i}^{t}\right)}{N} \\
P^{2}=\frac{\sum_{i=1}^{N}\left(\mu_{i}^{e}-\mu_{i}^{t}-A\right)^{2}}{N-1} \\
U^{2}=\frac{\sum_{i=1}^{N}\left(\mu_{i}^{e}-\mu_{i}^{t}\right)^{2}}{N}
\end{gathered}
$$

where

$$
\begin{aligned}
& \mu_{i}^{e}=\text { surface reflectance product } \\
& \mu_{i}^{t}=\text { surface reflectance 'truth' } \\
& N=\text { the total number of observations }
\end{aligned}
$$

\section{RESULTS AND DISCUSSION}

Considering that this study generated a large amount of data due to comparing each of the three analysed atmospheric corrected products, for each of the five study sites, for each spectral band of the used sensors, only the most significant data is presented here. The remaining graphics not displayed here, as well as scripts used to process the data and generate the results can be found on this article repository (https://github.com/marujore/Evaluatingthe-impact-of-LaSRC-and-Sen2cor-atmospheric-correctionalgorithms-on-Landsat-8-and-Sentin)

The total number of pixels for each analysis varies from band to band due to differences the product mask, since only pixels flagged as clear (pixels that aren't masked as cloud or cloud shadow) were considered in this analysis result.

\subsection{Landsat-8/OLI LaSRC}

Landsat-8/OLI LaSRC surface reflectance products were compared to the surface reflectance reference generated using ARCSI. This was performed by per-pixel comparison from the target and reference images, considering only pixels not assigned as cloud or cloud shadow, by the quality mask, on images from both sets. APU metrics were calculated for each study site and are shown in Table 2, and resulted in three types of scatter plots, Figure 4, Figure 3 and Figure 5 show their differences using blue (Band 2), red (Band 4) and SWIR 2 (Band 7) scatter plots and APU metrics obtained during the comparisons.

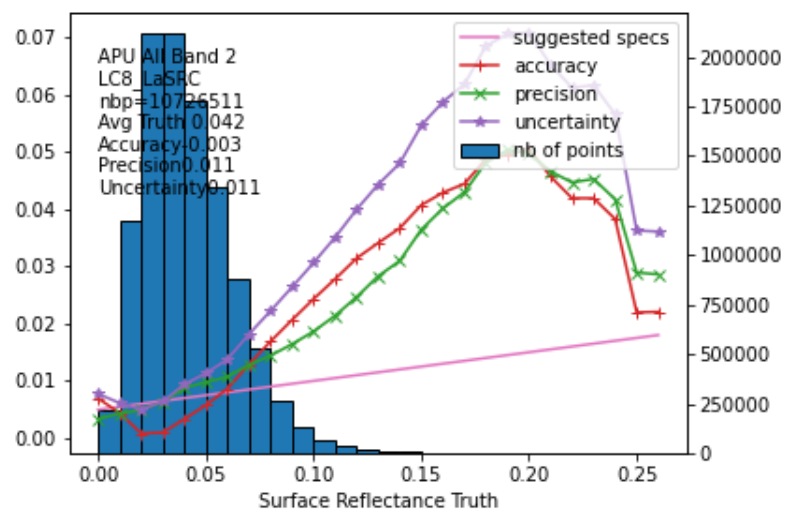

Figure 3. Scatter plot of Landsat-8/OLI Band 2 (Blue) image containing accuracy (red line), precision (green line), and uncertainty (blue line) as computed in bins (blue bars) where the magenta line represents the theoretical SR reference for Landsat SR $(0.005+0.05 \dot{\rho})$.

A, $\mathrm{P}$ and $\mathrm{U}$ values were frequently close to 0 for Landsat-8/OLI LaSRC results, meaning that the reference and target data were very similar. Most of the $U$ value found were beneath 0.022 , representing low uncertainties values in all stations, except for bands 1 and 2 (Coastal and Blue, respectively) in Rio Branco station (0.032 and 0.027 respectively). This AERONET station presented the worse APU results, probably associated to the high cloud cover in most part of the year in the Amazon region (Sanchez et al., 2020), as this station had lowest number of observations as presented at Table1.

The greater errors were found associated with the coastal and blue bands, band 1 and band 2 (Figure 4), respectively. Which is known to be the spectral region that has greatest atmospheric sensitivity (Vermote and Kotchenova, 2008, Claverie et al., 2015). The green and SWIR 2 bands (Figure 5), band 3 and 7, respectively, showed APU metrics bellow the theoretical SR 


\begin{tabular}{|c|c|c|c|c|c|c|}
\hline Band & Metric & Alta Floresta & Cuiabá-Miranda & Itajubá & Manaus & Rio Branco \\
\hline \multirow{3}{*}{1} & $\mathrm{~A}$ & -0.014 & -0.018 & -0.002 & -0.039 & -0.063 \\
& $\mathrm{P}$ & 0.017 & 0.012 & 0.010 & 0.013 & 0.032 \\
& $\mathrm{U}$ & 0.022 & 0.022 & 0.010 & 0.041 & 0.071 \\
\hline \multirow{3}{*}{2} & $\mathrm{~A}$ & -0.006 & -0.009 & 0.002 & -0.025 & -0.046 \\
& $\mathrm{P}$ & 0.012 & 0.009 & 0.007 & 0.011 & 0.027 \\
& $\mathrm{U}$ & 0.014 & 0.013 & 0.008 & 0.028 & 0.053 \\
\hline \multirow{3}{*}{3} & $\mathrm{~A}$ & -0.003 & -0.004 & 0.002 & -0.012 & -0.024 \\
& $\mathrm{P}$ & 0.005 & 0.005 & 0.004 & 0.005 & 0.012 \\
& $\mathrm{U}$ & 0.006 & 0.006 & 0.004 & 0.014 & 0.027 \\
\hline \multirow{3}{*}{4} & $\mathrm{~A}$ & -0.005 & -0.006 & -0.000 & -0.012 & -0.023 \\
& $\mathrm{P}$ & 0.006 & 0.005 & 0.003 & 0.006 & 0.012 \\
& $\mathrm{U}$ & 0.008 & 0.008 & 0.003 & 0.013 & 0.026 \\
\hline \multirow{3}{*}{5} & $\mathrm{~A}$ & -0.006 & -0.008 & 0.005 & -0.002 & -0.001 \\
& $\mathrm{P}$ & 0.012 & 0.012 & 0.005 & 0.001 & 0.004 \\
& $\mathrm{U}$ & 0.014 & 0.015 & 0.007 & 0.002 & 0.004 \\
\hline \multirow{3}{*}{6} & $\mathrm{~A}$ & -0.000 & -0.001 & 0.005 & 0.001 & 0.001 \\
& $\mathrm{P}$ & 0.007 & 0.009 & 0.003 & 0.001 & 0.002 \\
& $\mathrm{U}$ & 0.007 & 0.009 & 0.006 & 0.002 & 0.002 \\
\hline \multirow{2}{*}{7} & $\mathrm{~A}$ & -0.007 & -0.009 & -0.005 & -0.002 & -0.009 \\
& $\mathrm{P}$ & 0.007 & 0.008 & 0.004 & 0.001 & 0.005 \\
& $\mathrm{U}$ & 0.010 & 0.012 & 0.006 & 0.003 & 0.010 \\
\hline
\end{tabular}

Table 2. Landsat-8/OLI LaSRC surface accuracy (A), precision $(\mathrm{P})$ and uncertainty $(\mathrm{U})$ comparison between and reference data over all the sites.

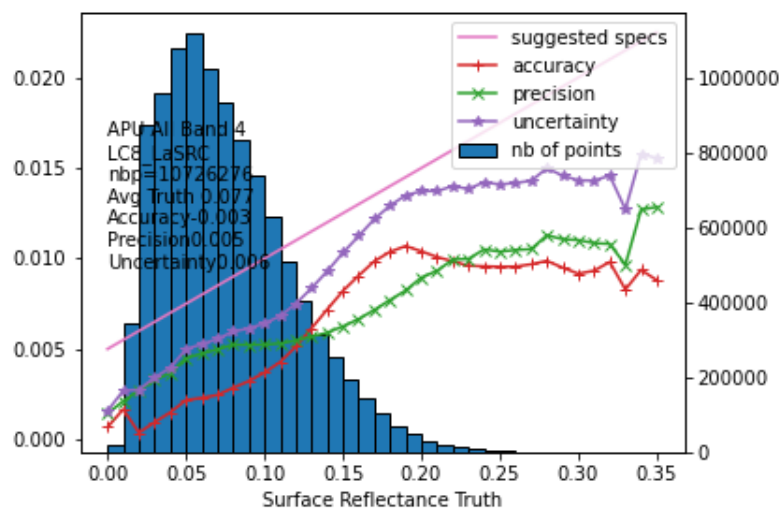

Figure 4. Scatter plot of Landsat-8/OLI Band 4 (Red) image containing accuracy (red line), precision (green line), and uncertainty (blue line) as computed in bins (blue bars) where the magenta line represents the theoretical SR reference for Landsat $\operatorname{SR}(0.005+0.05 \dot{\rho})$.

reference for most of the data with more uncertainty over the parcels with less observations. The red (band 4) scatter plot (Figure 3), which was very similar to bands 5 and 6 APU results were always under the theoretical SR reference. Considering all sites, the results obtained here were similar to the comparison performed by (Doxani et al., 2018), with the exception the band 7 plot. However, the only Brazilian site used on both studies was Alta Floresta and for this site the APU metric were almost entirely under the theoretical SR reference, as is in all sites evaluation (Figure 5).

\subsection{Sentinel-2/MSI LaSRC and Sen2cor}

Similarly to the Landsat-8/OLI LaSRC comparison, Sentinel2/MSI LaSRC and Sen2cor surface reflectance products were also compared to the surface reflectance reference provided by using ARCSI and the evaluation only used pixels that were clear on both images. APU metrics were calculated for each study site are shown in Table 3. Moreover, were produced two types of graphics, which are represented in Figure 6 using blue (Band

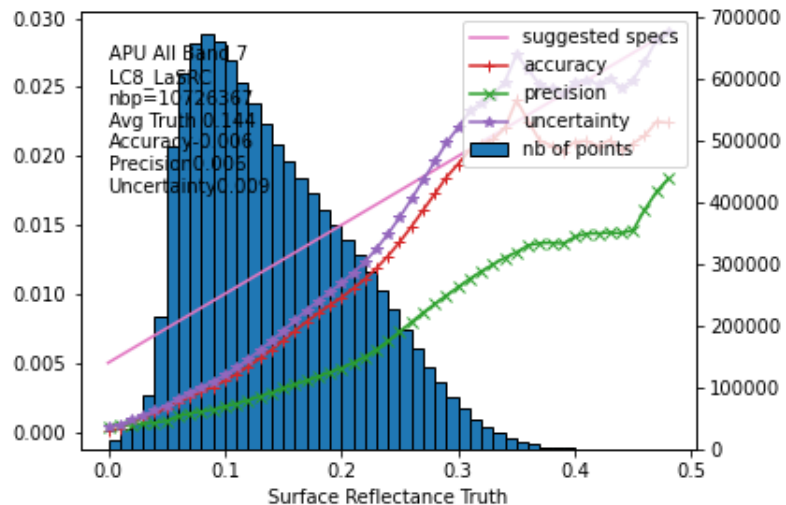

Figure 5. Scatter plot of Landsat-8/OLI Band 7 (Swir 2) image containing accuracy (red line), precision (green line), and uncertainty (blue line) as computed in bins (blue bars) where the magenta line represents the theoretical SR reference for Landsat $\mathrm{SR}(0.005+0.05 \dot{\rho})$.

2) and red (Band 4) bands as scatter plots and APU metrics obtained during the comparisons.

Atmospherically corrected Sentinel-2/MSI bands scatter plots presented two specific behaviors independent of the atmosphere correction processor, except for the blue band (band 2). This behaviors were: (i) APU close to the theoretical SR reference, as observed for most bands 4, 6, 8, 11 and 12 as illustrated in Figure $6 b, c$ and $d$; and (ii) APU that surpasses the theoretical SR reference during most part of the data, as observed mainly for bands 3, 5, 7 and 8A, represented in Figure $6 a$. The first type of scatter plots indicate a consistent atmosphere correction, while the second type may indicate modeling problems.

Comparing Sentinel-2/MSI results to the Landsat-8/OLI LaSRC results, the Sentinel-2/MSI using both LaSRC or Sen2cor presented greater APU values, with no band always under the theoretical SR reference. However, one point that should also be considered when comparing Sentinel-2/MSI LaSRC and Sen2cor results is that we considered as SR reference the results from ARCSI software, which uses the $6 \mathrm{~S}$ model to 


\begin{tabular}{|c|c|c|c|c|c|c|c|c|c|c|c|}
\hline \multirow{2}{*}{ Band } & \multirow[b]{2}{*}{ Metric } & \multicolumn{2}{|c|}{ Alta Floresta } & \multicolumn{2}{|c|}{ Cuiabá-Miranda } & \multicolumn{2}{|c|}{ Itajubá } & \multicolumn{2}{|c|}{ Manaus } & \multicolumn{2}{|c|}{ Rio Branco } \\
\hline & & LaSRC & Sen2cor & LaSRC & Sen 2 cor & LaSRC & Sen 2 cor & LaSRC & Sen 2 cor & LaSRC & Sen2cor \\
\hline \multirow{3}{*}{2} & $\mathrm{~A}$ & -0.014 & 0.003 & -0.010 & 0.001 & 0.000 & 0.005 & -0.012 & -0.005 & -0.012 & 0.016 \\
\hline & $\mathrm{P}$ & 0.024 & 0.018 & 0.014 & 0.009 & 0.014 & 0.014 & 0.009 & 0.007 & 0.016 & 0.012 \\
\hline & $\mathrm{U}$ & 0.028 & 0.019 & 0.017 & 0.009 & 0.014 & 0.015 & 0.015 & 0.009 & 0.020 & 0.020 \\
\hline \multirow{3}{*}{3} & A & -0.010 & 0.007 & -0.008 & 0.004 & 0.001 & 0.009 & -0.008 & 0.000 & -0.005 & 0.019 \\
\hline & $\mathrm{P}$ & 0.019 & 0.016 & 0.012 & 0.008 & 0.012 & 0.013 & 0.006 & 0.007 & 0.011 & 0.012 \\
\hline & $\mathrm{U}$ & 0.021 & 0.017 & 0.014 & 0.009 & 0.012 & 0.016 & 0.010 & 0.007 & 0.012 & 0.023 \\
\hline \multirow{3}{*}{4} & $\mathrm{~A}$ & -0.012 & 0.000 & -0.011 & -0.000 & -0.002 & 0.005 & -0.006 & -0.001 & -0.007 & 0.012 \\
\hline & $\mathrm{P}$ & 0.018 & 0.012 & 0.013 & 0.008 & 0.010 & 0.010 & 0.006 & 0.006 & 0.011 & 0.012 \\
\hline & $\mathrm{U}$ & 0.022 & 0.012 & 0.017 & 0.008 & 0.010 & 0.011 & 0.009 & 0.006 & 0.013 & 0.017 \\
\hline \multirow{3}{*}{5} & A & -0.026 & 0.001 & -0.021 & 0.003 & -0.009 & 0.006 & -0.015 & 0.002 & -0.011 & 0.027 \\
\hline & $\mathrm{P}$ & 0.020 & 0.014 & 0.016 & 0.011 & 0.013 & 0.016 & 0.006 & 0.008 & 0.011 & 0.012 \\
\hline & $\mathrm{U}$ & 0.033 & 0.014 & 0.026 & 0.012 & 0.016 & 0.017 & 0.017 & 0.009 & 0.015 & 0.029 \\
\hline \multirow{3}{*}{6} & A & -0.042 & -0.020 & -0.026 & -0.008 & -0.014 & 0.002 & -0.034 & -0.013 & -0.004 & 0.031 \\
\hline & $\mathrm{P}$ & 0.022 & 0.018 & 0.018 & 0.016 & 0.021 & 0.026 & 0.008 & 0.012 & 0.013 & 0.013 \\
\hline & $\mathrm{U}$ & 0.047 & 0.027 & 0.032 & 0.018 & 0.025 & 0.026 & 0.035 & 0.017 & 0.014 & 0.034 \\
\hline \multirow{3}{*}{7} & $\mathrm{~A}$ & -0.030 & -0.015 & -0.014 & -0.002 & 0.005 & 0.015 & -0.024 & -0.009 & 0.019 & 0.041 \\
\hline & $\mathrm{P}$ & 0.022 & 0.020 & 0.018 & 0.017 & 0.024 & 0.027 & 0.010 & 0.012 & 0.012 & 0.016 \\
\hline & $\mathrm{U}$ & 0.037 & 0.025 & 0.023 & 0.017 & 0.024 & 0.031 & 0.026 & 0.015 & 0.023 & 0.044 \\
\hline \multirow{3}{*}{8} & A & -0.041 & -0.023 & -0.024 & -0.008 & -0.011 & 0.009 & -0.034 & -0.017 & 0.003 & 0.031 \\
\hline & $\mathrm{P}$ & 0.024 & 0.019 & 0.020 & 0.016 & 0.025 & 0.027 & 0.009 & 0.013 & 0.016 & 0.015 \\
\hline & $\mathrm{U}$ & 0.048 & 0.030 & 0.031 & 0.018 & 0.027 & 0.029 & 0.035 & 0.022 & 0.016 & 0.034 \\
\hline \multirow{3}{*}{$8 \mathrm{~A}$} & A & -0.029 & -0.020 & -0.012 & -0.005 & 0.009 & 0.014 & -0.022 & -0.014 & 0.026 & 0.038 \\
\hline & $\mathrm{P}$ & 0.024 & 0.021 & 0.019 & 0.017 & 0.026 & 0.028 & 0.012 & 0.014 & 0.013 & 0.016 \\
\hline & $\mathrm{U}$ & 0.037 & 0.029 & 0.022 & 0.018 & 0.028 & 0.032 & 0.025 & 0.020 & 0.029 & 0.041 \\
\hline \multirow{3}{*}{11} & A & -0.028 & -0.008 & -0.015 & 0.002 & -0.002 & 0.009 & -0.014 & -0.001 & 0.011 & 0.034 \\
\hline & $\mathrm{P}$ & 0.020 & 0.018 & 0.016 & 0.015 & 0.018 & 0.019 & 0.008 & 0.008 & 0.008 & 0.011 \\
\hline & $\mathrm{U}$ & 0.034 & 0.020 & 0.022 & 0.015 & 0.018 & 0.021 & 0.016 & 0.008 & 0.014 & 0.035 \\
\hline \multirow{3}{*}{12} & A & -0.030 & -0.003 & -0.023 & 0.005 & -0.014 & 0.002 & -0.011 & 0.003 & -0.005 & 0.030 \\
\hline & $\mathrm{P}$ & 0.020 & 0.015 & 0.017 & 0.013 & 0.014 & 0.014 & 0.007 & 0.006 & 0.007 & 0.016 \\
\hline & $\mathrm{U}$ & 0.037 & 0.015 & 0.029 & 0.014 & 0.020 & 0.014 & 0.013 & 0.007 & 0.009 & 0.034 \\
\hline
\end{tabular}

Table 3. Sentinel-2/MSI LaSRC surface accuracy (A), precision (P) and uncertainty (U) comparison between and reference data over all the sites.
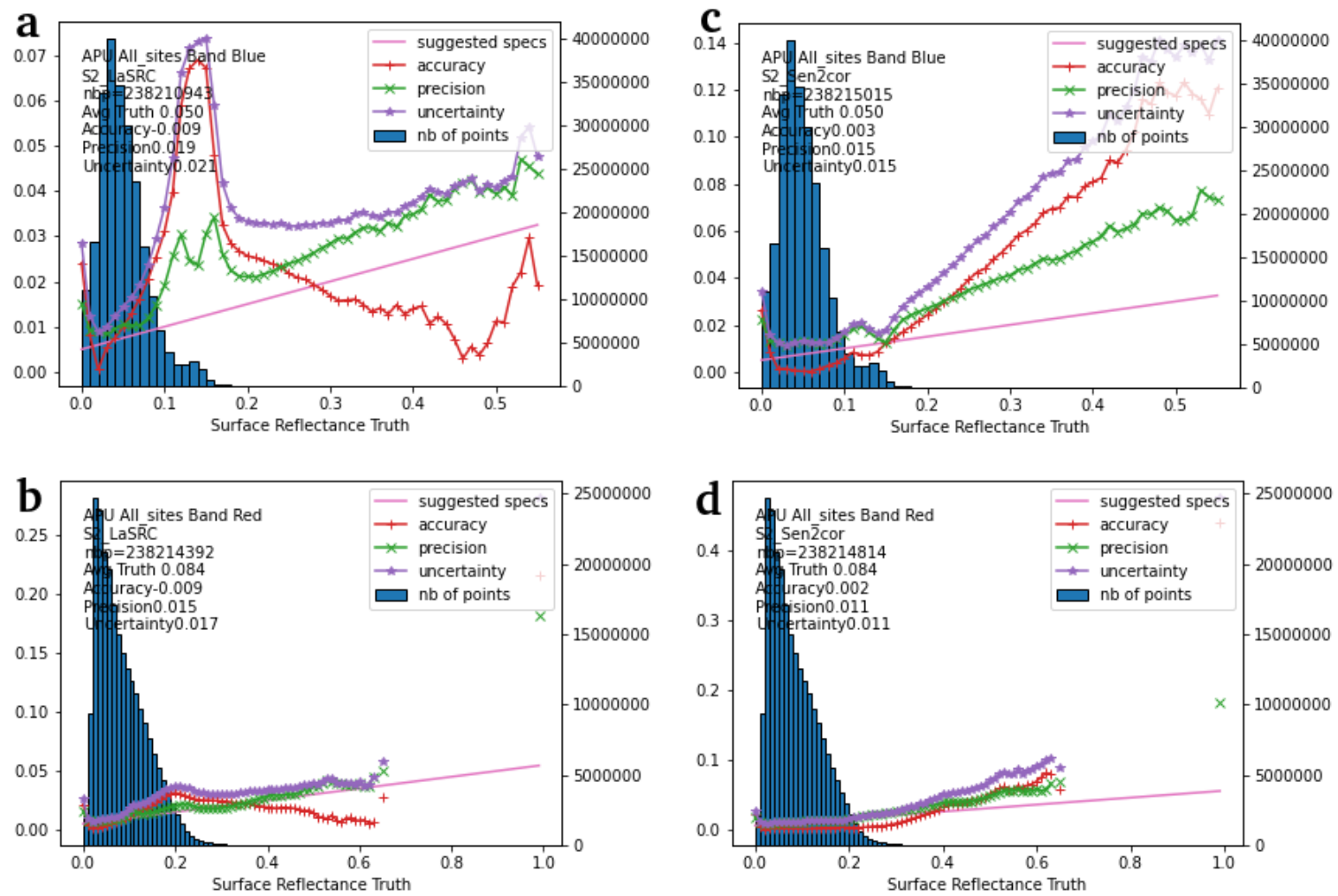

Figure 6. Scatter plots of Sentinel-2/MSI atmospherically corrected images containing accuracy (red line), precision (green line), and uncertainty (blue line) as computed in bins (blue bars) where the magenta line represents the theoretical SR reference for Sentinel SR $(0.005+0.05 \dot{\rho})$. (a): Band 2 (Blue) corrected with LaSRC; (b) Band 4 (Red) corrected with LaSRC; (c): Band 2 (Blue) corrected with Sen2cor; (d) Band 4 (Red) corrected with Sen2cor. 
correct the atmosphere effects, the same model LaSRC uses. This would benefit the LaSRC correction when compared to Sen2cor, meaning that the results using Sen2cor may be underestimated in the performed comparison. Even though, Sen2cor better performed the atmosphere correction. This behavior were most drastically in the blue band (band 2), as can be seen in Figure $6 a$ (LaSRC) and $c$ (Sen2cor).

These surface reflectance A, P, U results indicate that LaSRC perform a good atmospheric correction to Landsat- 8 data, supporting the findings of (Doxani et al., 2018). Moreover, Sentinel-2A/2B surface reflectance best results, regarding LaSRC and Sen2cor, were obtained using Sen2cor. Although, both results were satisfactory, Sentinel-2/MSI A, P, U results did not have similar performance as obtained by (Doxani et al., 2018).

\section{CONCLUSIONS}

Landsat-8/OLI images atmosphere correction was more consistent than the Sentinel-2/MSI images, when comparing to the reference surface reflectance. The LaSRC atmospheric correction over the Landsat-8/OLI images in Brazilian territory showed feasible surface reflectance values when compared to estimated surface reflectance reference. This was expected, since LaSRC was developed specifically for Landsat-8. However, it is always important to quantifying any discrepancies and verify the correctness of the product.

Considering Sentinel-2/MSI images, the Sen2cor correction outperformed the LaSRC correction and we could see their differences most on the blue (band 2) band. However, both methods presented elevated uncertainty, mainly for bands 3, 5, 7 and $8 \mathrm{~A}$, which could be due to the reference using a different atmospheric correction model than the atmospheric correction processor itself (Sen2cor), while for the remaining bands it showed $\mathrm{SR}$ values similar to the adopted reference.

Considering that both LaSRC and Sen2cor algorithms are being updated to newer versions (Main-Knorn et al., 2017), the advent of Landsat Collection-2 and the recent inter-comparison exercises (Doxani et al., 2018), it is expected that LaSRC and Sen2cor will converge to produce consistent and comparable data from both sensors. Based on that it is important to continue measuring the suitability of the atmospheric correction processors.

\section{ACKNOWLEDGEMENTS}

This research was supported by the Amazon Fund through the financial collaboration of the Brazilian Development Bank (BNDES) and the Foundation for Science, Technology and Space Applications (FUNCATE), process 17.2.0536.1; Thank AERONET Principal Investigators and their staff, the NASA Goddard AERONET site maintainers (https://aeronet.gsfc.nasa.gov), the European Space Agency and Copernicus program team, USGS Landsat program team, ARCSI developer and maintainer Dr. Pete Bunting and Dr. Robin Wilson for vast documentation and Py6S implementation.

\section{REFERENCES}

Appel, M., Pebesma, E., 2019. On-Demand Processing of Data Cubes from Satellite Image Collections with the gdalcubes Library. Data, 4(3), 92.
Asmaryan, S., Muradyan, V., Tepanosyan, G., Hovsepyan, A., Saghatelyan, A., Astsatryan, H., Grigoryan, H., Abrahamyan, R., Guigoz, Y., Giuliani, G., 2019. Paving the Way towards an Armenian Data Cube. Data, 4(3), 117.

Claverie, M., Vermote, E. F., Franch, B., Masek, J. G., 2015. Evaluation of the Landsat-5 TM and Landsat-7 ETM+ surface reflectance products. Remote Sensing of Environment, 169, 390-403.

Clewley, D., Bunting, P., Shepherd, J., Gillingham, S., Flood, N., Dymond, J., Lucas, R., Armston, J., Moghaddam, M., 2014. A Python-Based Open Source System for Geographic ObjectBased Image Analysis (GEOBIA) Utilizing Raster Attribute Tables. Remote Sensing, 6(7), 6111-6135.

Doxani, G., Vermote, E., Roger, J.-C., Gascon, F., Adriaensen, S., Frantz, D., Hagolle, O., Hollstein, A., Kirches, G., Li, F., Louis, J., Mangin, A., Pahlevan, N., Pflug, B., Vanhellemont, Q., 2018. Atmospheric Correction Inter-Comparison Exercise. Remote Sensing, 10(3), 352.

Ferreira, K. R., Queiroz, G. R., Vinhas, L., Marujo, R. F. B., Simoes, R. E. O., Picoli, M. C. A., Camara, G., Cartaxo, R., Gomes, V. C. F., Santos, L. A., Sanchez, A. H., Arcanjo, J. S., Fronza, J. G., Noronha, C. A., Costa, R. W., Zaglia, M. C., Zioti, F., Korting, T. S., Soares, A. R., Chaves, M. E. D., Fonseca, L. M. G., 2020. Earth Observation Data Cubes for Brazil: Requirements, Methodology and Products. Remote Sensing, 12(24), 4033.

Giuliani, G., Chatenoux, B., De Bono, A., Rodila, D., Richard, J.-P., Allenbach, K., Dao, H., Peduzzi, P., 2017. Building an Earth Observations Data Cube: Lessons Learned from the Swiss Data Cube (SDC) on Generating Analysis Ready Data (ARD). Big Earth Data, 1(1-2), 100-117.

Holben, B. N., Eck, T. F., Slutsker, I., Tanré, D., Buis, J. P., Setzer, A., Vermote, E., Reagan, J. A., Kaufman, Y. J., Nakajima, T., Lavenu, F., Jankowiak, I., Smirnov, A., 1998. AERONET-A Federated Instrument Network and Data Archive for Aerosol Characterization. Remote Sensing of Environment, 66(1), 1-16.

Ilori, C., Pahlevan, N., Knudby, A., 2019. Analyzing Performances of Different Atmospheric Correction Techniques for Landsat 8: Application for Coastal Remote Sensing. Remote Sensing, 11(4), 469.

Ju, J., Roy, D. P., Vermote, E., Masek, J., Kovalskyy, V., 2012. Continental-scale validation of MODIS-based and LEDAPS Landsat ETM+ atmospheric correction methods. Remote Sensing of Environment, 122, 175-184.

Killough, B., 2019. The Impact of Analysis Ready Data in the Africa Regional Data Cube. IGARSS 2019 - 2019 IEEE International Geoscience and Remote Sensing Symposium, IEEE, Yokohama, Japan, 5646-5649.

King, M. D., Kaufman, Y. J., Tanré, D., Nakajima, T., 1999. Remote Sensing of Tropospheric Aerosols from Space: Past, Present, and Future. Bulletin of the American Meteorological Society, 80(11), 2229-2260.

Kuenzer, C., Dech, S., Wagner, W., 2015. Remote Sensing Time Series. Remote Sensing and Digital Image Processing, 22, Springer International Publishing, Cham. 
Lewis, A., Oliver, S., Lymburner, L., Evans, B., Wyborn, L., Mueller, N., Raevksi, G., Hooke, J., Woodcock, R., Sixsmith, J., Wu, W., Tan, P., Li, F., Killough, B., Minchin, S., Roberts, D., Ayers, D., Bala, B., Dwyer, J., Dekker, A., Dhu, T., Hicks, A., Ip, A., Purss, M., Richards, C., Sagar, S., Trenham, C., Wang, P., Wang, L.-W., 2017. The Australian Geoscience Data Cube - Foundations and Lessons Learned. Remote Sensing of Environment, 202, 276-292.

Li, Z., Roy, D., Zhang, H., Vermote, E., Huang, H., 2019. Evaluation of Landsat- 8 and Sentinel-2A Aerosol Optical Depth Retrievals across Chinese Cities and Implications for Medium Spatial Resolution Urban Aerosol Monitoring. Remote Sensing, 11(2), 122.

Main-Knorn, M., Pflug, B., Louis, J., Debaecker, V., MüllerWilm, U., Gascon, F., 2017. Sen2Cor for Sentinel-2. 3.

Maso, J., Zabala, A., Serral, I., Pons, X., 2019. A Portal Offering Standard Visualization and Analysis on top of an Open Data Cube for Sub-National Regions: The Catalan Data Cube Example. Data.

Qiu, S., Zhu, Z., He, B., 2019. Fmask 4.0: Improved cloud and cloud shadow detection in Landsats $4-8$ and Sentinel-2 imagery. Remote Sensing of Environment, 231, 111205.

Sanchez, A. H., Picoli, M. C. A., Camara, G., Andrade, P. R., Chaves, M. E. D., Lechler, S., Soares, A. R., Marujo, R. F. B., Simões, R. E. O., Ferreira, K. R., Queiroz, G. R., 2020. Comparison of Cloud Cover Detection Algorithms on Sentinel-2 Images of the Amazon Tropical Forest. Remote Sensing, 12(8), 1284 .

Siqueira, A., Lewis, A., Thankappan, M., Szantoi, Z., Goryl, P., Labahn, S., Ross, J., Hosford, S., Mecklenburg, S., Tadono, T., Rosenqvist, A., Lacey, J., 2019. CEOS Analysis Ready Data For Land - An Overview on the Current and Future Work. 5536-5537.

Vermote, E. F., Kotchenova, S., 2008. Atmospheric correction for the monitoring of land surfaces. Journal of Geophysical Research Atmospheres, 113(23), 1-12.

Vermote, E., Justice, C., Claverie, M., Franch, B., 2016. Preliminary analysis of the performance of the Landsat 8/OLI land surface reflectance product. Remote Sensing of Environment, 185, $46-56$.

Vermote, E., Roger, J. C., Franch, B., Skakun, S., 2018. LASRC (Land Surface Reflectance Code): Overview, application and validation using MODIS, VIIRS, LANDSAT and Sentinel 2 data's. International Geoscience and Remote Sensing Symposium (IGARSS), 2018-July, 8173-8176. 